\title{
Proteomic and Morphologic Evidence for Taurine-5-Bromosalicylaldehyde Schiff Base as an Efficient Anti-Mycobacterial Drug's
}

\author{
Wenyong Ding ${ }^{1 \dagger}$, Houli Zhang ${ }^{2 \dagger}$, Yuefei $\mathrm{Xu}^{1}$, $\mathrm{Li} \mathrm{Ma}^{3}$, and Wenli Zhang ${ }^{1 *}$ \\ ${ }^{1}$ Biochemistry and Molecular Biology Department, College of Basic Medical Sciences, Dalian Medical University, Dalian 116044, P.R. China \\ ${ }^{2}$ Institute of Pharmacology, Dalian Medical University, Dalian 116044, P.R. China \\ ${ }^{3}$ Department of Epidemiology, Dalian Medical University, Dalian 116044, P.R. China
}

\author{
Received: January 10, 2019 \\ Revised: January 28, 2019 \\ Accepted: July 24, 2019 \\ First published online \\ July 25, 2019 \\ *Corresponding author \\ Phone: +86-13591799210 \\ Fax: +86-411-86110312; \\ E-mail: zhangwenli@dlmedu.edu.cn \\ ${ }^{\dagger}$ These authors contributed \\ equally to this work. \\ S upplementary data for this \\ paper are available on-line only at \\ http://jmb.or.kr. \\ pISSN 1017-7825, eISSN 1738-8872 \\ Copyright(C) 2019 by \\ The Korean Society for Microbiology \\ and Biotechnology
}

\begin{abstract}
Mycobacterium tuberculosis, a causative pathogen of tuberculosis (TB), still threatens human health worldwide. To find a novel drug to eradicate this pathogen, we tested taurine-5bromosalicylaldehyde Schiff base (TBSSB) as an innovative anti-mycobacterial drug using Mycobacterium smegmatis as a surrogate model for $M$. tuberculosis. We investigated the antimicrobial activity of TBSSB against $M$. smegmatis by plotting growth curves, examined the effect of TBSSB on biofilm formation, observed morphological changes by scanning electron microscopy and transmission electron microscopy, and detected differentially expressed proteins using two-dimensional gel electrophoresis coupled with mass spectrometry. TBSSB inhibited mycobacterial growth and biofilm formation, altered cell ultrastructure and intracellular content, and inhibited cell division. Furthermore, M. smegmatis adapted itself to TBSSB inhibition by regulating the metabolic pathways and enzymatic activities of the identified proteins. NDMA-dependent methanol dehydrogenase, $\mathrm{NAD}(\mathrm{P}) \mathrm{H}$ nitroreductase, and amidohydrolase AmiB1 appear to be pivotal factors to regulate the M. smegmatis survival under TBSSB. Our dataset reinforced the idea that Schiff base-taurine compounds have the potential to be developed as novel anti-mycobacterial drugs.
\end{abstract}

Keywords: Mycobacterium, tuberculosis, taurine-5-bromosalicylaldehyde Schiff base, morphology, cell wall, two-dimensional gel electrophoresis

\section{Introduction}

Mycobacterium tuberculosis, a causative pathogen of tuberculosis (TB), has evolved to multidrug-resistant/ rifampin resistant (MDR/RR)- or extensively drug-resistant (XDR)-M. tuberculosis, and remains a major threat to human health worldwide. According to the 2018 WHO global TB report, 3.5\% of new TB cases (an estimated 10 million of new TB cases in 2017) and 18\% of previously treated TB cases were estimated to be MDR-TB/RR-TB globally, and the treatment success rates for the cases with MDR-TB/RRTB were much lower (only approximately 55\%) based on the current anti-TB treatment regiments [1]. In addition, TB treatment required long-term medication. M. tuberculosis infection therefore imposes a heavy economic burden on the global economy. On the other hand, the increasing rise of MDR/RR-M. tuberculosis strains has promoted a significant worldwide effort to discover innovative anti-TB drugs for their eradication.

As therapeutic agents, Schiff base complexes have been intensively investigated due to their antifungal, anticancer, and antibacterial properties [2-5]. Schiff bases, named after the chemist Hugo Schiff [6], contain a functional double bond between carbon and nitrogen which can mimic the structural features of the biological regulator's active sites. In addition, Schiff base complexes derived from salicylaldehyde and amino acids have recently attracted great attention. Taurine, a sulfur-containing amino acid, is essential to human beings as it has a variety of physiological functions such as modulation of neurotransmitters, hormone release regulation, and neuronal excitability $[2,7]$. In this study, taurine-5-bromosalicylaldehyde Schiff base (TBSSB), a taurine 


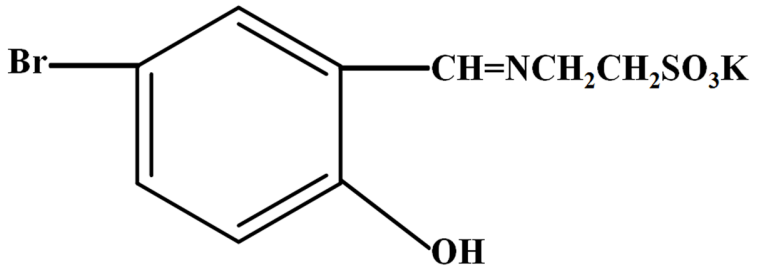

Fig. 1. Taurine-5-bromosalicylaldehyde Schiff base (TBSSB) in complex with potassium.

Schiff base complex with potassium, was synthesized from the condensation of the amine group of taurine and the active aldehyde group of the aromatic compound (Fig. 1), and its structure was confirmed by spectral infrared radiation (IR) and single-crystal X-ray diffraction [8].

Our previous studies demonstrated that TBSSB is an effective and attractive drug against planktonic MRSA [8]. However, little is known about the roles of TBSSB in mycobacteria. Based on the results in planktonic MRSA, it was estimated that TBSSB could also be effective against M. tuberculosis because they are all gram-positive bacteria. However, it is known that the walls of mycobacteria cells usually prevent drugs from entering the bacteria. In this study we investigated the antibacterial activity of TBSSB against M. smegmatis, commonly used in mycobacterial research as a surrogate model for the pathogenic and slower-growing M.tuberculosis, to reveal the influence of TBSSB on mycobacterial survival and the regulation mechanism of mycobacteria grown under TBSSB. Our results provide the evidence to support the use of TBSSB for anti-TB drug design and underscore the significance of TBSSB as an anti-mycobaterial drug.

\section{Materials and Methods}

\section{Strains and Chemicals}

M. smegmatis $\mathrm{mc}^{2} 155$ cells from the ATCC were routinely cultivated in Luria-Bertani (LB, Oxoid Ltd., England) broth with $0.05 \%$ Tween 80 or on LB agar at $37^{\circ} \mathrm{C}$. TBSSB was synthesized and confirmed as described previously [8].

\section{Growth Monitoring of the M. smegmatis}

A single colony of wild-type $M$. smegmatis was inoculated into $5 \mathrm{ml} \mathrm{LB}$ broth for $48 \mathrm{~h}$. Then $20 \mu \mathrm{l}$ of the culture was added to $20 \mathrm{ml}$ LB broth containing $0.05 \%$ Tween 80 , and TBSSB was added at a gradient with final concentrations of $0,25,40,50,60$, and $75 \mu \mathrm{g} / \mathrm{ml}$. The growth of M. smegmatis was determined by monitoring the optical density (OD) at $600 \mathrm{~nm}$ of cultures at intervals of $12 \mathrm{~h}$ using a Multiskan FC microplate reader (Thermo
Scientific, USA). Growth curves were plotted with $\mathrm{OD}_{600 \mathrm{~nm}}$ versus incubation time, and the optimal inhibition factors were determined from the incubation time and TBSSB concentration.

\section{Morphologic Observation by Scanning Electron Microscopy (SEM) and Transmission Electron Microscopy (TEM)}

M. smegmatis cells treated with TBSSB were harvested after 40-h incubation followed by fixation in $2.5 \%$ glutaraldehyde in $100 \mathrm{mM}$ PBS (pH 7.4). Fixed M. smegmatis cell pellets were further fixed in $100 \mathrm{mM}$ ( $\mathrm{pH} 7.4$ ) with $1 \%$ osmium tetroxide $\left(\mathrm{OsO}_{4}\right)$, and dehydrated in a gradient series of $20 \%, 40 \%, 60 \%, 70 \%, 80 \%, 90 \%$, and $100 \%$ ethanol. For SEM analysis, dehydrated cell pellets were resuspended in $100 \%$ ethanol, applied to a silicon wafer slide, and gold-coated to a thickness of $5 \mathrm{~nm}$. The cells were examined with a JSM-6500F scanning electron microscope using an accelerating voltage of $15 \mathrm{kV}$. For TEM analysis, the dehydrated cells were embedded using an Epon 812 embedding kit and cut into ultrathin sections. The sections were then stained with both uranyl acetate and lead nitrate, and the cell morphology was observed using a JEM2000EX TEM (JEOL, JAPAN) [9]. M. smegmatis cells not treated with TBSSB were used as the control.

\section{Biofilm Assays}

M. smegmatis cells inoculated in LB broth and incubated at $37^{\circ} \mathrm{C}$ to 0.5 of $\mathrm{OD}_{600 \mathrm{~nm}}$, were transferred to $\mathrm{M} 63$ medium $(0.5 \%$ Casamino acids, $1 \mathrm{mM} \mathrm{MgSO}_{4} 0.7 \mathrm{mM} \mathrm{CaCl}_{2}$ ) at a dilution rate of $1: 1000$. TBSSB was added into the medium at a gradient of final concentrations of $0,25,40,50,60$, and $75 \mu \mathrm{g} / \mathrm{ml}$. A $150 \mu$ culture was added to each well in a 96-well polystyrene microtiter plate (Costar, USA). The plates were incubated at $30^{\circ} \mathrm{C}$ for 5 days without shaking. After incubation, the wells were rinsed three times with $200 \mu \mathrm{l}$ physiological saline to remove unattached bacteria, and stained with $150 \mu \mathrm{l}$ of $1 \%$ crystal violet (SigmaAldrich, USA) for $15 \mathrm{~min}$ at room temperature. The plates were rinsed with water three times to remove the excess dye. Stain was resolubilized with $150 \mu \mathrm{l}$ of $95 \%$ ethanol and the $\mathrm{OD}_{595 \mathrm{~nm}}$ was read in a microplate reader (Thermo Scientific). The test of biofilm formation was performed in triplicate.

\section{Two-Dimensional Electrophoresis and Image Analyses}

Soluble protein was extracted from the harvested M. smegmatis cells treated with TBSSB and processed by a Cleanup Kit (Bio-Rad, USA) according to the manufacturer's instructions. Processed protein pellets were dissolved in $50 \mu \mathrm{l}$ IEF buffer $(7 \mathrm{M}$ urea, $2 \mathrm{M}$ thiourea, $2 \%(\mathrm{w} / \mathrm{v}$ ) CHAPS, and $30 \mathrm{mM}$ Tris $\mathrm{pH} 8.0)$, and the total soluble protein was quantified using a BCA Protein Kit assay (keyGEN BioTECH, China). Fifty micrograms of total soluble protein was subjected to bidimensional (2D) electrophoresis analysis (Protein IEF Cell, Bio-Rad). The subsequent 2D electrophoresis analysis and the image analyses were performed as described previously [10]. Proteins were separated in the first dimension using Immobiline DryStrips (11 cm, pH 4-7, Bio-Rad), and in the second dimension using $12 \%$ SDS-PAGE gels. The gels 
were stained using a ProteoSilver Plus SilverStain Kit (SigmaAldrich). Gel image analysis and statistical quantification were conducted using PDQuest software. Student's t-test was used to assess the statistical significance of the differentially expressed proteins based on average spot volume ratio. The protein spots with a fold-change (FC) $\geq 2$ or $\leq 0.5$ at $95 \%$ confidence level (Student t-test; $p<0.05$ ) were selected for further mass spectrometry (MS) identification. The spots located near the gel borders and the small or faint spots were excluded from protein identification. M. smegmatis cells not treated with TBSSB were used as the control.

\section{Trypsin Digestion, MS/MS Analysis and Data Acquisition}

The selected protein spots were excised manually from the gels, and the subsequent decolorization using $100 \mathrm{mM} \mathrm{NH}_{4} \mathrm{HCO}_{3} / 30 \%$ ACN with $\mathrm{K}_{3} \mathrm{Fe}(\mathrm{CN})_{6}$ and $\mathrm{Na}_{2} \mathrm{~S}_{2} \mathrm{O}_{3}$, and in-gel trypsin digestion using $100 \mathrm{mM} \mathrm{NH}_{4} \mathrm{HCO}_{3}$ containing $12.5 \mathrm{ng} / \mu$ l sequencing-grade trypsin for $20 \mathrm{~h}$ at $37^{\circ} \mathrm{C}$ were conducted as described previously [11]. MS identification was conducted using a 5800 MALDI-TOF/ TOF MS (Applied Biosystems, USA) in positive ionization mode and automatic data acquisition mode. The following optimized source/gas parameters were used: the instrument contained a $\mathrm{Nd}$ :YAG laser; the mass analyzer scan was $800-4,000 \mathrm{Da} \mathrm{m} / \mathrm{z}$; ions were accelerated with a voltage of $2 \mathrm{kV}$, and CID in the off setting. Data were acquired using Mascot 2.2 software. MS spectra were searched against the NCBI database. Confidence in peptide identifications was assessed based on the MASCOT sequence assignment score and visual inspection of the molecular mass and pI values of the selected spots in the gels.

\section{Bioinformatics Analysis}

Analysis on functional classification of proteins was performed for the differentially expressed proteins identified by tandem mass spectrometry. The 14 gene symbols in $M$. tuberculosis with corresponding homology to the proteins identified in M. smegmatis

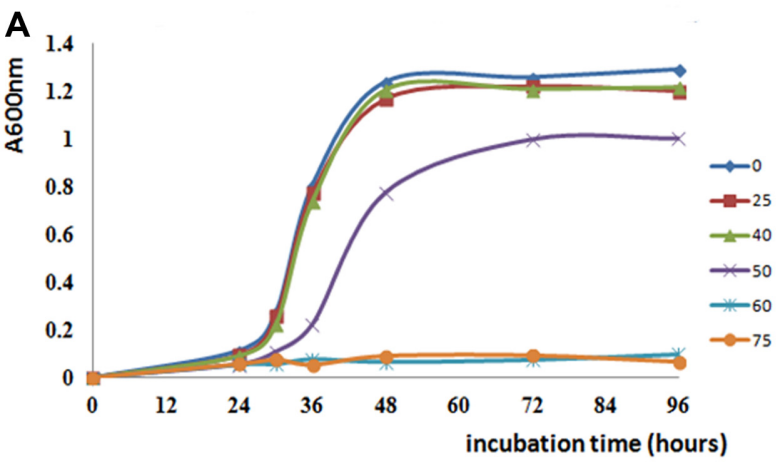

were entered into the PANTHER database (http:/ / www.pantherdb. org/) for functional classification. The 20 gene symbols in $M$. smegmatis were input to STRING (https://string-db.org/cgi/ input.pl) for protein network construction.

\section{Results}

\section{Determination of TBSSB-Dose Dependent Growth}

The effect of TBSSB was assayed on M. smegmatis cultures. Growth curves were plotted as $\mathrm{OD}_{600 \mathrm{~nm}}$ versus cultivation time. A TBSSB-dose dependent growth curve of M. smegmatis was established by the gradient of $0-75 \mu \mathrm{g} / \mathrm{ml}$ TBSSB concentrations. Fig. 2A shows that $>60 \mu \mathrm{g} / \mathrm{ml}$ TBSSB completely inhibited M. smegmatis growth, whereas < $40 \mu \mathrm{g} / \mathrm{ml}$ TBSSB did not have an obvious inhibitory effect on growth, and $50 \mu \mathrm{g} / \mathrm{ml}$ TBSSB showed an optimally inhibitory growth. The optimally inhibitory growth was determined with $50 \mu \mathrm{g} / \mathrm{ml}$ TBSSB for $40 \mathrm{~h}$.

\section{Decreased Biofilm Formation of M. smegmatis Inhibited by TBSSB}

To further investigate the effect of TBSSB on mycobacterial growth, inhibition by TBSSB of biofilm formation by M. smegmatis was assessed. As shown in Fig. 2B, a TBSSBdose dependent inhibition in biofilm formation was revealed. Even though the growth curve did not display an obvious inhibition with $40 \mu \mathrm{g} / \mathrm{ml}$ TBSSB, a significant decrease in the biofilm formation was detected in $M$. smegmatis grown at a lower TBSSB concentration. Statistical analysis of the crystal violet staining showed that TBSSB had a dose-dependent significant inhibition on M. smegmatis biofilm formation.

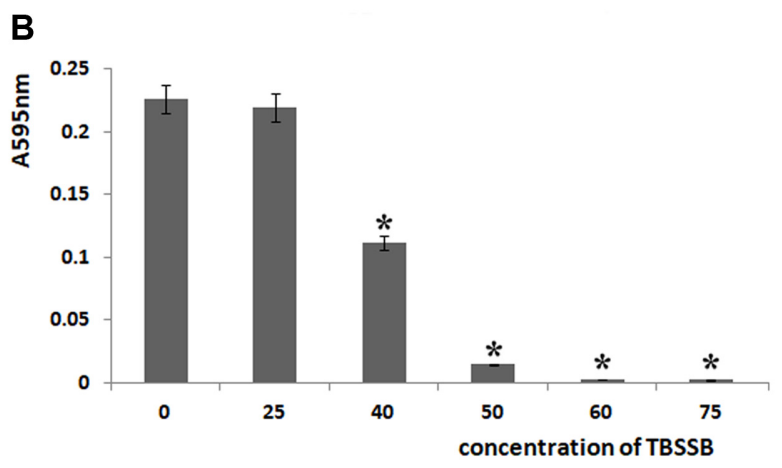

Fig. 2. Influence of TBSSB on growth and biofilm formation of M. smegmatis.

(A) M. smegmatis grown under TBSSB. Cell growth was monitored at $600_{\mathrm{nm}}$ with values plotted from triplicate experiments. Final TBSSB concentrations included: $0 \mu \mathrm{g} / \mathrm{ml}$ (dark blue), $25 \mu \mathrm{g} / \mathrm{ml}$ (red), $40 \mu \mathrm{g} / \mathrm{ml}$ (green), $50 \mu \mathrm{g} / \mathrm{ml}$ (purple), $60 \mu \mathrm{g} / \mathrm{ml}$ (light blue) and $75 \mu \mathrm{g} / \mathrm{ml}$ (orange). (B) Statistical analysis of biofilm formation. M. smegmatis cells were exposed to TBSSB concentrations ranging from 0 to $75 \mu \mathrm{g} / \mathrm{ml}$. Bars represent the mean \pm SEM; $p<0.05 *$ was considered significant. 

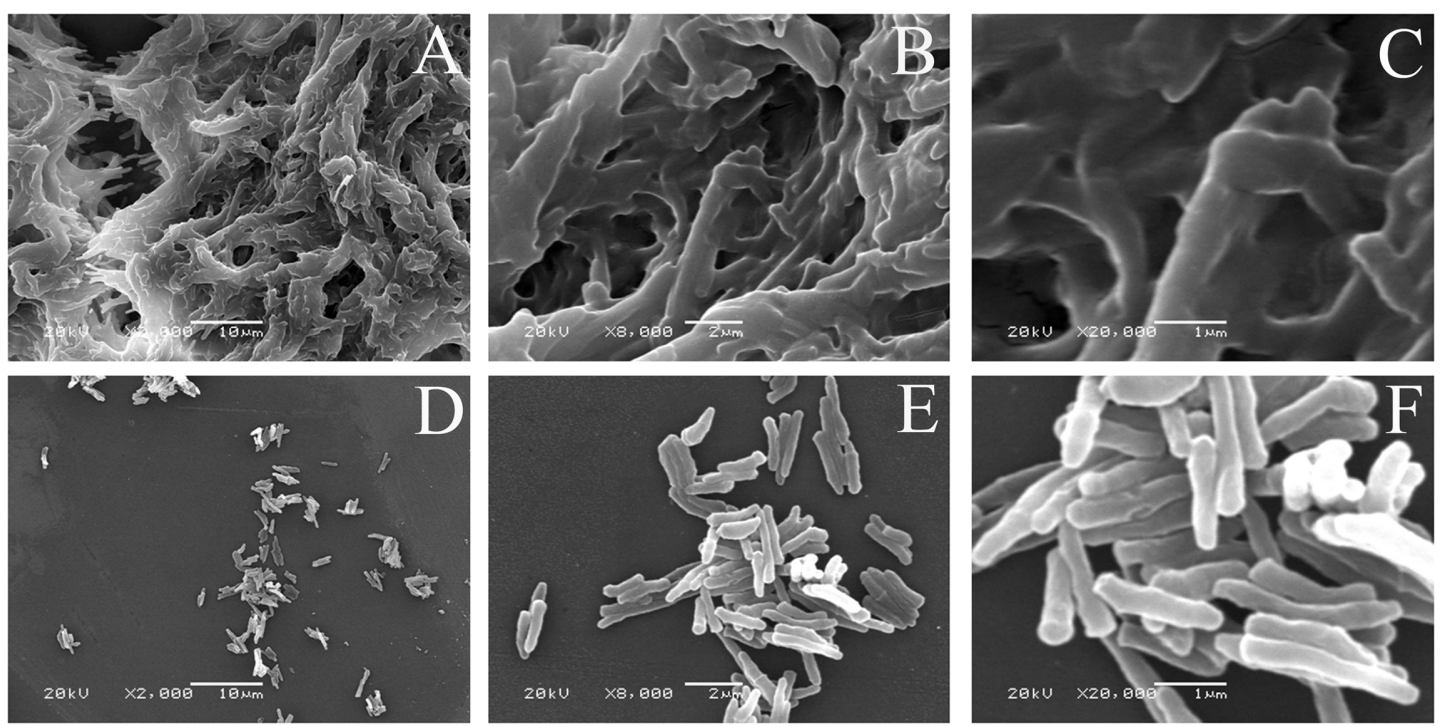

Fig. 3. Representative SEM micrographs of M. smegmatis.

M. smegmatis cells exposed to TBSSB at $50 \mu \mathrm{g} / \mathrm{ml}(\mathbf{A}-\mathbf{C})$ and $0 \mu \mathrm{g} / \mathrm{ml}(\mathbf{D}-\mathbf{F})$. Magnification: A and C, 2,000x; B and E, 8,000x; C and F, 20,000x.

\section{Morphological Alterations of M. smegmatis Inhibited by TBSSB}

Morphology of M. smegmatis grown under $50 \mu \mathrm{g} / \mathrm{ml}$ TBSSB was observed by TEM and SEM using non-TBBSBtreated M. smegmatis as the control. SEM images are shown in Fig. 3. Non-TBBSB-treated M. smegmatis cells had a clear cell shape, and appeared as straight, thin rods with a smooth cell surface. In contrast, the TBBSB-treated M. smegmatis cells displayed a warped cell morphology without a defined and clear cell borderline and appeared to be fused together as shown in Figs. 3A, 3B, and 3C. No independent cells and integrated cell wall were found in SEM images. In addition, compared with the morphological micrographs obtained in planktonic MRSA, TBSSB showed a higher destruction of the cell wall in M. smegmatis than planktonic MRSA.

TEM images are displayed in Fig. 4. Compared with the images from non-TBBSB-treated $M$. smegmatis cells, alteration of the cytosolic content was observed in TBBSB-treated M. smegmatis cells based on electron density. Non-TBBSBtreated M. smegmatis had filamentous DNA and clear nucleoid region visible within cells, whereas TBBSB-treated M. smegmatis displayed a rearrangement of the intracellular contents including an invisible nucleoid region and concentrated cytosolic materials represented by high electron-dense bodies. Additionally, a dramatic increase in numbers of Z-ring, a typical marker of cell division, was observed in TBBSB-treated M. smegmatis (Fig. 4B). Based on this observation, TBSSB appears to block M. smegmatis cell division to further inhibit its growth. Furthermore, more M. smegmatis cells displaying a longitudinal sectional view were found when inhibited by TBSSB. M. smegmatis cells usually have a firm and rigid cell envelope to protect them against adverse conditions, and it is hard to obtain wild M. smegmatis cells with longitudinal sectional view using the TEM analysis. All this evidence pointed to the fact that TBBSB-treated M. smegmatis cells have an attenuated cell envelope and were easily cut using the TEM technique.

\section{Identification of Differentially Expressed Proteins by 2D-} Gel Electrophoresis Coupled with Mass Spectrometry

To search for differentially expressed proteins, we performed a pairwise comparison of TBSSB-treated and non-TBSSB-treated M. smegmatis cells. Proteome changes in gel were automatically analyzed by PDQuest software, and the spots corresponding to the most prominent changes in terms of fold-change (ratios $<0.05$ and $>2$ ) and statistical significance $(p<0.05)$ were selected. Fig. 5 shows the paired 2D-gel images manually labeled according to their numbers obtained from the PDQuest analysis. Considering the spot intensities and their locations on the 2D-gel images, 20 spots with significantly differential expression (Table 1) were extracted for further MS identification. Of the 20 spots, seven spots showed a $\geq 2$-fold up-regulation, whereas 13 showed a $\leq 0.5$-fold down-regulation in TBSSBtreated compared to non-TBSSB-treated M. smegmatis cells.

Seven proteins (alanine dehydrogenase, Myo-inositol 2dehydrogenase, hemerythrin HHE cation-binding protein, 

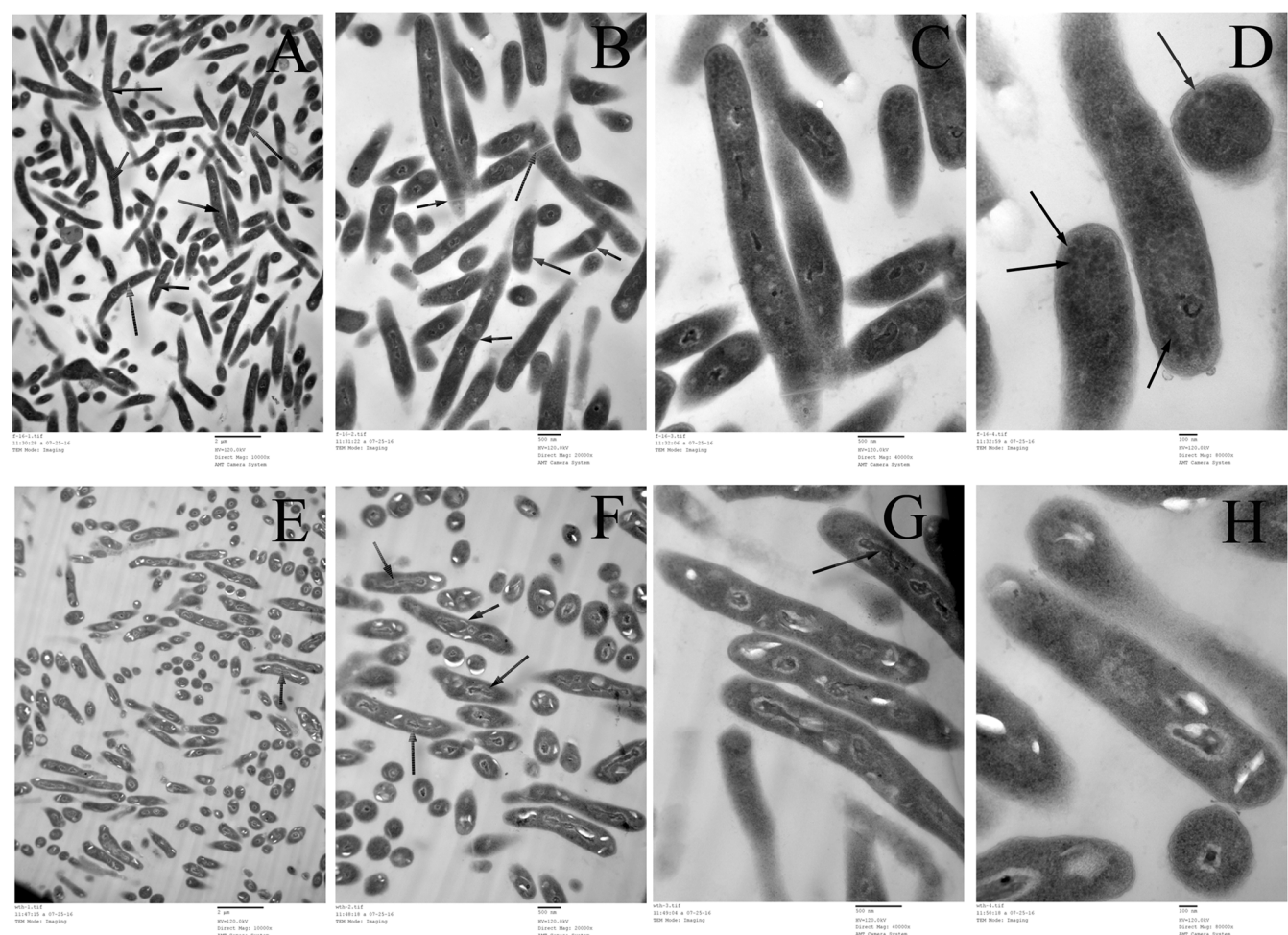

Fig. 4. Representative TEM micrographs of $M$. smegmatis cells grown with TBSSB at $50 \mu \mathrm{g} / \mathrm{ml}(\mathrm{A}-\mathrm{D})$ and $0 \mu \mathrm{g} / \mathrm{ml}(\mathrm{E}-\mathrm{H})$. Magnification: A and E, 10,000x; B and F, 20,000x; C and G, 40,000x; D and E, 60,000x. High electron-dense bodies indicated by arrows in D; filamentous DNA and clear nucleoid region indicated by arrows in F and G; M. smegmatis cells with longitudinal sectional view indicated by arrows in $\mathrm{A}$ and $\mathrm{E}$; Z-rings indicated by arrows in $\mathrm{B}$.

3-beta hydroxysteroid dehydrogenase, molecular chaperone DnaK, mannose-binding lectin, and pyridoxal 5'-phosphate synthase lyase subunit PdxS) were up-regulated in TBSSBtreated M. smegmatis cells. Fourteen proteins including glycerate kinase, bifunctional 5,10-methylene-tetrahydro- folate-dehydrogenase /5,10-methylene-tetrahydrofolate cyclohydrolase, aldehyde dehydrogenase, isochorismatase hydrolase, hypothetical protein MSMEG_1680, eptc-inducible aldehyde dehydrogenase, forkhead-associated protein, $\mathrm{NAD}(\mathrm{P}) \mathrm{H}$ nitroreductase, oligopeptide transport ATP-

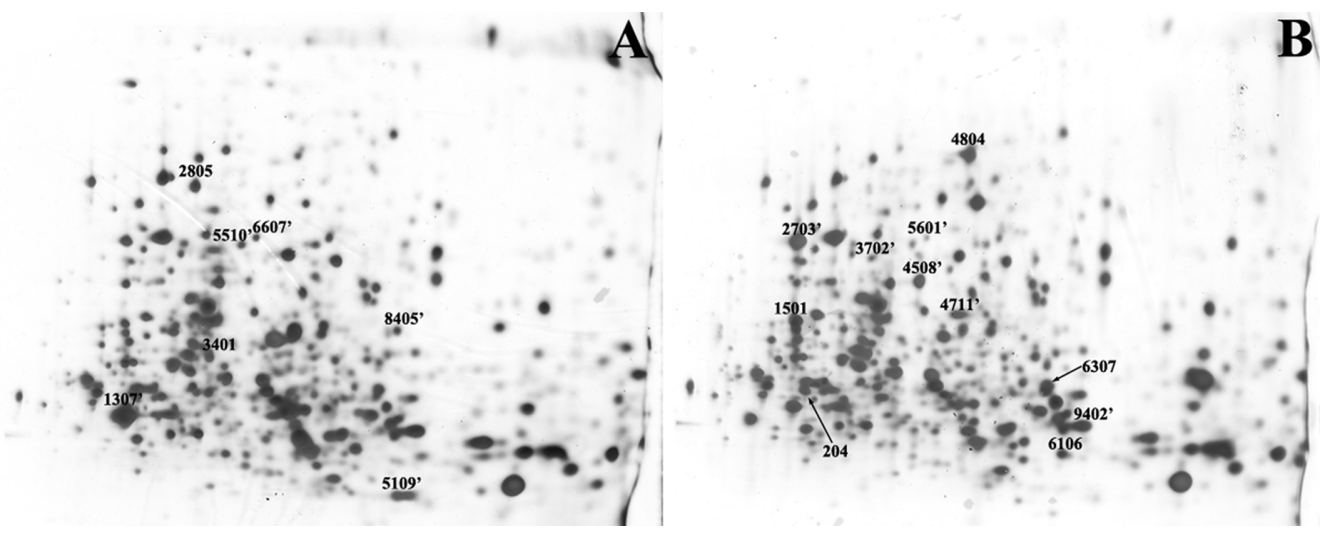

Fig. 5. Representative maps of differentially expressed proteins identified by 2D-gel electrophoresis analysis.

A pairwise comparison was performed between TBSSB-treated M. smegmatis cells (A) and TBSSB non-treated cells (B). Gels were visualized after silver staining. Numbers labeled manually according to SSP numbers by PDQuest analysis. 
Table 1. Properties of the differentially expressed proteins identified by MS.

\begin{tabular}{|c|c|c|c|c|c|c|c|c|c|c|}
\hline SSN & $\begin{array}{l}\text { TBSSB/ } \\
\text { WT } \\
\text { Ratio }\end{array}$ & Protein Name & $\begin{array}{c}\text { NCBI } \\
\text { Accession No. }\end{array}$ & $\begin{array}{l}\text { No. in } \\
\text { M. smegmatis }\end{array}$ & $\begin{array}{l}\text { No. in } \\
\text { M. tuberculosis }\end{array}$ & $\begin{array}{l}\text { Protein } \\
\text { MW }\end{array}$ & $\begin{array}{l}\text { Protein } \\
\text { PI }\end{array}$ & $\begin{array}{l}\text { Pep. } \\
\text { Count }\end{array}$ & $\begin{array}{c}\text { Protein } \\
\text { Score }\end{array}$ & $\begin{array}{l}\text { Protein } \\
\text { Score } \\
\text { C. I. \% }\end{array}$ \\
\hline 2805 & 14.49 & Alanine dehydrogenase & Q8KY18.1 & MSMEG_2659 & $\operatorname{Rv} 2780$ & 38931 & 5.56 & 15 & 74 & 99.704 \\
\hline 3401 & 10.73 & $\begin{array}{l}\text { Myo-inositol 2- } \\
\text { dehydrogenase }\end{array}$ & CKI19118.1 & MSMEG_4650 & & 35303.6 & 4.93 & 15 & 108 & 100 \\
\hline 3104 & 0.12 & glycerate kinase & WP_058125940.1 & MSMEG_2528 & Rv1437 & 37686.7 & 4.49 & 14 & 64 & 97.478 \\
\hline 4804 & 0.14 & $\begin{array}{l}\text { bifunctional 5,10- } \\
\text { methylene- } \\
\text { tetrahydrofolatedehydroge } \\
\text { nase/5,10-methylene- } \\
\text { tetrahydrofolate } \\
\text { cyclohydrolase }\end{array}$ & YP_886023.1 & MSMEG_1647 & Rv3356c & 29674.7 & 5.9 & 12 & 61 & 94.482 \\
\hline 204 & 0.18 & aldehyde dehydrogenase & CKG90698.1 & MSMEG_0309 & Rv0223c & 52014.4 & 4.65 & 17 & 72 & 99.541 \\
\hline 6106 & 0.24 & isochorismatase hydrolase & YP_889227.1 & MSMEG_4976 & & 20686.6 & 4.67 & 8 & 72 & 99.519 \\
\hline 6307 & 0.45 & $\begin{array}{l}\text { hypothetical protein } \\
\text { MSMEG_1680 }\end{array}$ & YP_886056.1 & MSMEG_1680 & & 23529.9 & 4.74 & 4 & 71 & 99.732 \\
\hline 1501 & 0.45 & $\begin{array}{l}\text { eptc-inducible aldehyde } \\
\text { dehydrogenase }\end{array}$ & YP_885925.1 & MSMEG_1543 & Rv0458 & 55944.1 & 5.01 & 4 & 117 & 100 \\
\hline $8405^{\prime}$ & 5.56 & $\begin{array}{l}\text { hemerythrin HHE cation- } \\
\text { binding protein }\end{array}$ & YP_886755.1 & MSMEG_2415 & & 21247.8 & 4.82 & 10 & 182 & 100 \\
\hline $6607^{\prime}$ & 4.51 & $\begin{array}{l}\text { 3-beta hydroxysteroid } \\
\text { dehydrogenase }\end{array}$ & AIU08609.1 & MSMEG_3470 & Rv3785 & 31062.9 & 5.14 & 9 & 307 & 100 \\
\hline $5510^{\prime}$ & 3.06 & $\begin{array}{l}\text { pyridoxal } 5^{\prime} \text {-phosphate } \\
\text { synthase lyase subunit } \\
\text { PdxS }\end{array}$ & WP_011728705.1 & MSMEG_2937 & Rv2606c & 32082.3 & 5.11 & 8 & 119 & 100 \\
\hline $5109^{\prime}$ & 2.89 & mannose-binding lectin & AIU08795.1 & MSMEG_3662 & & 21909 & 4.54 & 8 & 62 & 97.924 \\
\hline $1307^{\prime}$ & 2.44 & molecular chaperone DnaK & YP_885116.1 & MSMEG_0709 & Rv0350 & 66606.2 & 4.71 & 33 & 539 & 100 \\
\hline $9402^{\prime}$ & 0.3 & $\begin{array}{l}\text { forkhead-associated } \\
\text { protein }\end{array}$ & AIU06864.1 & MSMEG_1634 & $\operatorname{Rv} 3863$ & 20435.1 & 4.86 & 7 & 63 & 98.312 \\
\hline $5601^{\prime}$ & 0.27 & $\mathrm{NAD}(\mathrm{P}) \mathrm{H}$ nitroreductase & AIU10280.1 & MSMEG_5246 & Rv2032 & 36198.5 & 5.19 & 12 & 106 & 100 \\
\hline $4508^{\prime}$ & 0.18 & $\begin{array}{l}\text { oligopeptide transport } \\
\text { ATP-binding protein OppD }\end{array}$ & YP_885050.1 & MSMEG_0640 & Rv1281c & 36035.5 & 5.05 & 14 & 68 & 99.466 \\
\hline $4711^{\prime}$ & 0.22 & $\begin{array}{l}\text { tetrahydropicolinate } \\
\text { succinylase }\end{array}$ & YP_889353.1 & MSMEG_5104 & & 32430.7 & 5.38 & 12 & 61 & 97.067 \\
\hline $4701^{\prime}$ & 0.23 & Amidohydrolase AmiB1 & YP_886055.1 & MSMEG_1679 & Rv3306c & 40703.4 & 5.39 & 15 & 125 & 100 \\
\hline $3702^{\prime}$ & 0.41 & $\begin{array}{l}\text { NDMA-dependent } \\
\text { methanol dehydrogenase }\end{array}$ & WP_011731151.1 & MSMEG_6242 & $\operatorname{Rv} 3692$ & 46262 & 5.36 & 19 & 240 & 100 \\
\hline $2703^{\prime}$ & 0.45 & $\begin{array}{l}\text { methylmalonate- } \\
\text { semialdehyde } \\
\text { dehydrogenase }\end{array}$ & YP_885880.1 & MSMEG_1498 & $\operatorname{Rv} 0753 c$ & 54269.7 & 5.31 & 21 & 173 & 100 \\
\hline
\end{tabular}

binding protein $\mathrm{OppD}$, tetrahydropicolinate succinylase, amidohydrolase AmiB1, N-nitrosodimethylamine (NDMA)dependent methanol dehydrogenase, and methylmalonatesemialdehyde dehydrogenase were significantly downregulated in TBSSB-treated M. smegmatis cells (Table 1).

\section{Discussion}

In this study we found that TBSSB affects M. smegmatis cells to attenuate the cell envelope. The mycobacterial cell wall consists of a cell wall core with an inner plasma 
membrane. The core structure of the cell wall (mAGP, mycolic acids-arabinogalactan-peptidoglycan) is composed of three covalently linked substructures: peptidoglycan $(\mathrm{PG})$, arabinogalactan (AG) and mycolic acids. The innermost layer consists of PGs covalently attached to the middle layer of AG (a polysaccharide of arabinose and galactose sugars) via a phosphoryl- $N$-acetylglucosaminosylrhamnosyl linkage. AG is esterified with the outer layer of mycolic acids containing long-chain fatty acids (C60-C90) [12-14]. Both AG and PG are hydrophilic, but mycolic acids are highly hydrophobic. This relatively impermeable cell wall usually serves as a natural barrier against harmful compounds and factors that inhibit growth, and is essential for mycobacterial survival. Most anti-mycobacterial drugs have been designed to target the mycobacterial cell envelope, especially the enzymes involved in cell wall biosynthesis [15-17]. In this study we found that TBSSB efficiently targeted the mycobacterial cell envelope and led to cell wall destruction. Moreover, TBSSB displayed a more efficient inhibition on M. smegmatis cells than on planktonic MRSA. For these reasons, TBSSB has significant potential to be developed into anti-mycobacterial drug.

Morphological images obtained in this study displayed a vast majority of M. smegmatis cells fused together to form complex communities where they lived and died. Recently, a number of intriguing observations have suggested that microorganisms likely evolved programmed cell death
(PCD) in response to damage, antibiotics, environmental stimuli or other harmful conditions [18]. PCD is a genetically encoded process that leads to cell death. It plays a critical role in many developmental processes and homeostasis in bacteria [19]. Damaged bacteria undergoing PCD possibly are of benefit to the whole microbial community because they donate nutrients to neighboring cells for repairing them instead of draining resources from their neighbors. This phenomenon is noted as altruistic cell death accompanied by autolysis of mother cells. Autolysis is a self-digestion of the cell wall catalyzed by peptidoglycan hydrolases [18]. It was interesting to note that the amidohydrolase AmiB1, one important autolysin, had been detected using proteomic techniques in this study. AmiB plays an important role in cell division and cell lysis [18, 20, 21]. In this study, we found that AmiB (MSMEG_1679) down-regulated altruistic behavior of microorganisms by forming a regulation network with MSMEG_1680 and DapD (MSMEG_5104) (Fig. 6A), and that downregulation of this network plays a pivotal role in protecting live M. smegmatis cells from autolysis.

To reveal a possible in vivo regulation mechanism on $M$. smegmatis cells exposed to TBSSB, the proteomic analysis on soluble proteins was carried out by 2D-gel electrophoresis coupled with tandem mass spectrometry analysis. As a consequence, 20 proteins were identified to be significantly regulated. Of the 20 identified proteins, seven were
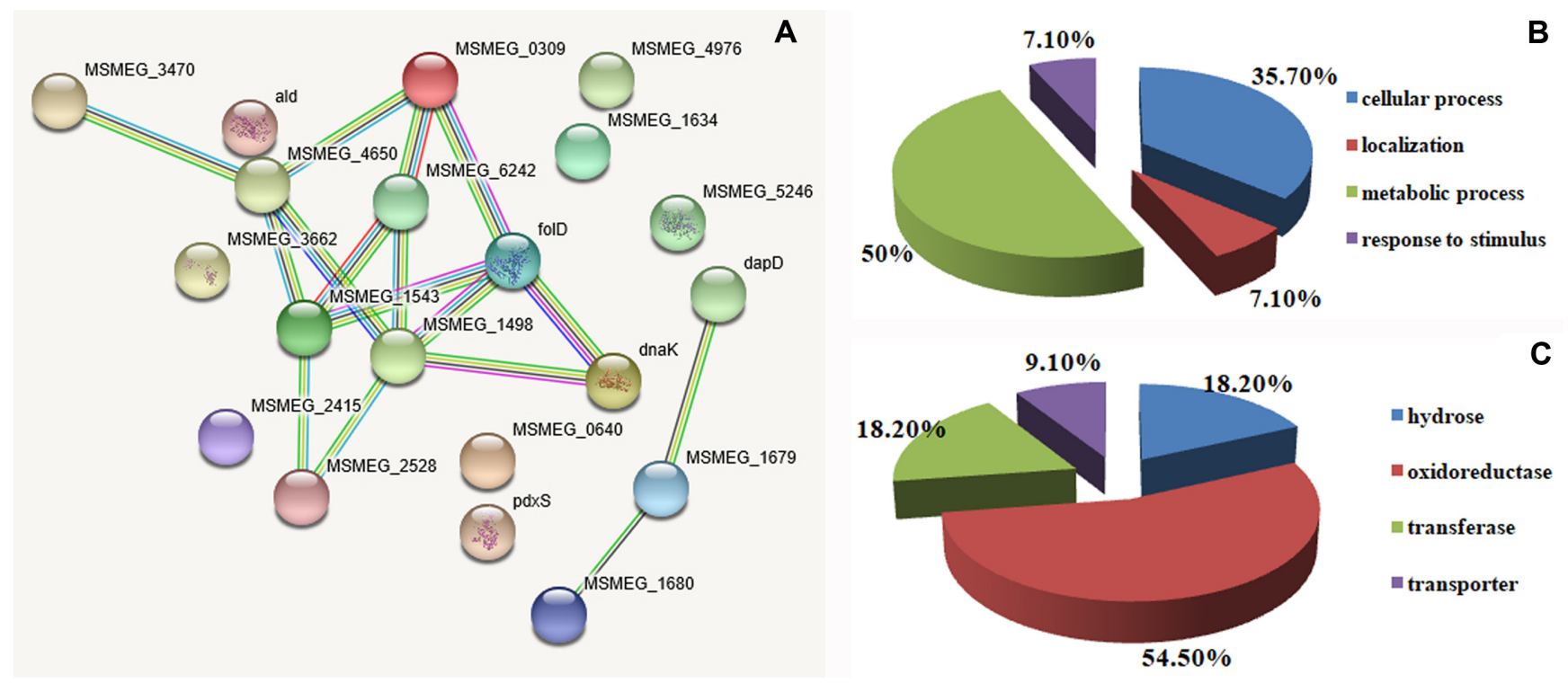

Fig. 6. Bioinformatic analysis of the differentially expressed proteins identified by tandem mass spectrometry.

(A) Protein-protein interaction networks analysis using STRING database, (B) and (C) protein classification analysis using PANTHER database. The representative pie diagram displayed the involvement percentage for differently functional categories of the proteins. (B) Proteins categorized into groups according to the biological process; (C) proteins categorized into groups according to the protein class. 
upregualted and 13 were downregulated. To gain functional information of these identified proteins in the dataset, we searched their corresponding homologous proteins in M. tuberculosis for functional classification in PANTHER. The pie diagram of Figs. 6B and 6C displays graphically the involvement percentage of the identified proteins for different functional categories. Proteins with high involvement were in the oxidoreductase class (54.5\%); other functional categories were hydrolase $(18.2 \%)$, transferase $(18.2 \%)$, and transporter (9.1\%) (Fig. 6C). They respond to biological processes including metabolic $(50.0 \%)$, cellular $(35.7 \%)$, response to stimulus $(7.1 \%)$ and localization $(7.1 \%)$ processes (Fig. 6B). Thus, cell survival was regulated via altering the metabolic pathway and enzymatic activities of the identified protein.

Interestingly, NDMA-dependent methanol dehydrogenase (MSMEG_6242) and NAD(P)H nitroreductase (MSMEG_5246) were identified as differentially expressed proteins in this study; they had been identified in $M$. smegmatis grown under DdlA deficiency as well. DdlA is a ligase that catalyzes the dimerization of two D-alanine molecules yielding D-alanyl-D-alanine, which is an indispensable substrate for peptidoglycan biosynthesis [10]. MSMEG_5246 has been documented previously as an $\mathrm{NAD}(\mathrm{P}) \mathrm{H}$ nitroreductase [22], proteins which have a remarkable ability to catalyze reduction of nitroaromatic compounds to their corresponding hydroxylaminoaromatics via ionic or radical mechanisms [23]. Nitroreductases have been proved as targets for eradication of various pathogens by widely used antibiotics such as nifurtimox, nitrofurantoin and metronidazole [24]. NDMA-dependent methanol dehydrogenase (MSMEG_6242) allows Gram-negative microorganisms to generate energy from methanol oxidation and synthesize compounds with carbon-carbon bonds from methanol assimilation [25]. In this study, MSMEG_6242 was found to interact directly with MSMEG_0309, MSMEG_1543, MSMEG_1498 to form a network that also showed a strongly positive interaction with the other five identified proteins including MSMEG_1647, MSMEG_0409, MSMEG_2528, MSMEG_4650 and MSMEG_3470 to regulate $M$. smegmatis survival (Fig. 6A). Thus, MSMEG_6242 and MSMEG_5246 play a pivotal role in regulating $M$. smegmatis survival under adverse conditions and have potential as an anti-mycobacterial drug target.

In this study, M. smegmatis $\mathrm{mc}^{2} 155$ was used as the surrogate model for pathogenic and slow-growing $M$. tuberculosis [26-30]. Compared to M. tuberculosis, M. smegmatis has a variety of advantages: (1) It grows faster [30] since its doubling time is around $5 \mathrm{~h}$ against $30 \mathrm{~h}$ for M. tuberculosis [31, 32]; (2) it is non-pathogenic [1]; (3) has a unique cell wall similar to that of $M$. tuberculosis which plays a crucial role in cell survival and growth under adverse environmental conditions or drug resistance [16, 17]; (4) it is closely related to $M$. tuberculosis in species and genetics according to phylogenetic tree analysis. Therefore, it is applicable for $M$. smegmatis to be utilized as the surrogate host of $M$. tuberculosis in vivo.

Taken together, we report here that TBSSB inhibits mycobacterial growth and biofilm formation, attenuated cell division and cell wall ultrastructure, and altered the intracellular mycobacterial content. Additionally, metabolic pathways were regulated to adapt $M$. smegmatis to TBSSB inhibition. Among the 20 differentially expressed proteins identified, NDMA-dependent methanol dehydrogenase, $\mathrm{NAD}(\mathrm{P}) \mathrm{H}$ nitroreductase, and amidohydrolase AmiB1 were found to be critical in regulating $M$. smegmatis survival exposed to TBSSB. Our study reinforces the idea that Schiff base-taurine compounds have great potential to be developed as novel anti-mycobacterial drugs.

\section{Acknowledgments}

This work was supported by the National Natural Science Foundation of China (81272429) and Liaoning Provincial Program for Top Discipline of Basic Medical Sciences.

\section{Conflict of Interest}

The authors have no financial conflicts of interest to declare.

\section{References}

1. Organization WH. 2018. GLOBAL TUBERCULOSIS REPORT 2018. http://www.who.int/tb/publications/global_report/en/.

2. Rîmbu C, Danac R, Pui A. 2014. Antibacterial activity of $\operatorname{Pd}(\mathrm{II})$ complexes with salicylaldehyde-amino acids Schiff bases ligands. Chem. Pharm. Bull. (Tokyo) 62: 12-15.

3. Chaudhary NK, Mishra P. 2017. Metal complexes of a novel schiff base based on penicillin: characterization, molecular modeling, and antibacterial activity study. Bioinorg. Chem. Appl. 2017: 6927675.

4. Siddappa K, Mayana NS. 2014. Synthesis, spectroscopic characterization, and biological evaluation studies of 5bromo-3-(((hydroxy-2-methylquinolin-7-yl)methylene)hydrazono) indolin-2-one and its metal (II) complexes. Bioinorg. Chem. Appl. 2014: 483282.

5. Andiappan K, Sanmugam A, Deivanayagam E, Karuppasamy K, Kim HS, Vikraman D. 2018. In vitro cytotoxicity activity 
of novel Schiff base ligand-lanthanide complexes. Sci. Rep. 8(1): 3054

6. Zhang X, Bi C, Fan Y, Cui Q, Chen D, Xiao Y, et al. 2008. Induction of tumor cell apoptosis by taurine Schiff base copper complex is associated with the inhibition of proteasomal activity. Int. J. Mol. Med. 22: 677-682.

7. Li L, Guo Q, Dong J, Xu T, Li J. 2013. DNA binding, DNA cleavage and BSA interaction of a mixed-ligand copper(II) complex with taurine Schiff base and 1,10-phenanthroline. J. Photochem. Photobiol. B. 125: 56-62.

8. Yuan R, Diao Y, Zhang W, Lin Y, Huang S, Zhang H, et al. 2014. In vitro activity of taurine-5-bromosalicylaldehyde Schiff base against planktonic and biofilm cultures of methicillinresistant Staphylococcus aureus. J. Microbiol. Biotechnol. 24: 1059-1064.

9. Zhang W, Jones VC, Scherman MS, Mahapatra S, Crick D, Bhamidi S, et al. 2008. Expression, essentiality, and a microtiter plate assay for mycobacterial GlmU, the bifunctional glucosamine-1-phosphate acetyltransferase and $\mathrm{N}$-acetylglucosamine-1-phosphate uridyltransferase. Int. J. Biochem. Cell Biol. 40: 2560-2571.

10. Chen Y, Xu Y, Yang S, Li S, Ding W, Zhang W. 2019. Deficiency of D-alanyl-D-alanine ligase A attenuated cell division and greatly altered the proteome of Mycobacterium smegmatis. MicrobiologyOpen 3: e819.

11. Yang S, Xu Y, Wang Y, Ren F, Li S, Ding W, et al. 2018. The biological properties and potential interacting proteins of Dalanyl-D-alanine ligase A from Mycobacterium tuberculosis. Molecules 23: E324.

12. Marland Z, Beddoe T, Zaker-Tabrizi L, Coppel RL, Crellin PK, Rossjohn J. 2005. Expression, purification, crystallization and preliminary X-ray diffraction analysis of an essential lipoprotein implicated in cell-wall biosynthesis in Mycobacteria. Acta crystallogr. Sec. F, Struct. Biol. Cryst. Commun. 61: 1081-1083.

13. Pan F, Jackson M, Ma Y, McNeil M. 2001. Cell wall core galactofuran synthesis is essential for growth of mycobacteria. J. Bacteriol. 183: 3991-3998.

14. Kieser KJ, Baranowski C, Chao MC, Long JE, Sassetti CM, Waldor MK, et al. 2015. Peptidoglycan synthesis in Mycobacterium tuberculosis is organized into networks with varying drug susceptibility. Proc. Nat. Acad. Sci. USA 112: $13087-13092$.

15. Rombouts Y, Brust B, Ojha AK, Maes E, Coddeville B, ElassRochard E, et al. 2012. Exposure of mycobacteria to cell wallinhibitory drugs decreases production of arabinoglycerolipid related to Mycolyl-arabinogalactan-peptidoglycan metabolism. J. Biol. Chem. 287: 11060-11069.

16. Alderwick LJ, Harrison J, Lloyd GS, Birch HL. 2015. The mycobacterial cell wall--peptidoglycan and arabinogalactan. Cold Spring Harb. Perspect. Med. 5: a021113.

17. Jankute M, Cox JA, Harrison J, Besra GS. 2015. Assembly of the mycobacterial cell wall. Ann. Rev. Microbiol. 69: 405-423.

18. Lewis K. 2000. Programmed death in bacteria. Microbiol. Mol. Biol. Rev. 64: 503-514.
19. Tanouchi Y, Lee AJ, Meredith H, You L. 2013. Programmed cell death in bacteria and implications for antibiotic therapy. Trends Microbiol. 21: 265-270.

20. Peters NT, Dinh T, Bernhardt TG. 2011. A fail-safe mechanism in the septal ring assembly pathway generated by the sequential recruitment of cell separation amidases and their activators. J. Bacteriol. 193: 4973-4983.

21. Yang DC, Tan K, Joachimiak A, Bernhardt TG. 2012. A conformational switch controls cell wall-remodelling enzymes required for bacterial cell division. Mol. Microbiol. 85: 768-781.

22. Chauviac F-X, Bommer M, Yan J, Parkin G, Daviter T, Lowden P, et al. 2012. Crystal structure of reduced MsAcg, a putative nitroreductase from mycobacterium smegmatisand a close homologue of mycobacterium tuberculosis Acg. J. Biol. Chem. 287: 44372-44383.

23. Pitsawong W, Haynes CA, Koder RL, Jr., Rodgers DW, Miller AF. 2017. Mechanism-informed refinement reveals altered substrate-binding mode for catalytically competent nitroreductase. Structure 25: 978-987.

24. Cortial S, Chaignon P, Iorga BI, Aymerich S, Truan G, Gueguen-Chaignon V, et al. 2010. NADH oxidase activity of Bacillus subtilis nitroreductase NfrA1: insight into its biological role. FEBS Lett. 584: 3916-3922.

25. Hektor HJ, Kloosterman H, Dijkhuizen L. 2002. Identification of a magnesium-dependent $\operatorname{NAD}(\mathrm{P})(\mathrm{H})$-binding domain in the nicotinoprotein methanol dehydrogenase from Bacillus methanolicus. J. Biol. Chem. 277: 46966-46973.

26. Liu H, Yang M, He ZG. 2016. Novel TetR family transcriptional factor regulates expression of multiple transport-related genes and affects rifampicin resistance in Mycobacterium smegmatis. Sci. Rep. 6: 27489.

27. Titgemeyer F, Amon J, Parche S, Mahfoud M, Bail J, Schlicht $\mathrm{M}$, et al. 2007. A genomic view of sugar transport in Mycobacterium smegmatis and Mycobacterium tuberculosis. J. Bacteriol. 189: 5903-5915.

28. Valente W, Pienaar E, Fast A, Fluitt A, Whitney S, Fenton R, et al. 2009. A Kinetic Study of In vitro lysis of mycobacterium smegmatis. Chem. Eng. Sci. 64: 1944-1952.

29. Agrawal P, Miryala S, Varshney U. 2015. Use of Mycobacterium smegmatis deficient in ADP-ribosyltransferase as surrogate for Mycobacterium tuberculosis in drug testing and mutation analysis. PLoS One 10: $\mathrm{e} 0122076$.

30. Namouchi A, Cimino M, Favre-Rochex S, Charles P, Gicquel B. 2017. Phenotypic and genomic comparison of Mycobacterium aurum and surrogate model species to Mycobacterium tuberculosis: implications for drug discovery. BMC Genomics 18(1): 530.

31. Verma A, Sampla AK, Tyagi JS. 1999. Mycobacterium tuberculosis rrn promoters: differential usage and growth rate-dependent control. J. Bacteriol. 181: 4326-4333.

32. Manca C, Paul S, Barry CEr, Freedman VH, Kaplan G. 1999. Mycobacterium tuberculosis catalase and peroxidase activities and resistance to oxidative killing in human monocytes in vitro. Infect. Immun. 67: 74-79. 